Provided for non-commercial research and educational use. Not for reproduction, distribution or commercial use.

This article was originally published in the Encyclopedia of Inland Waters published by Elsevier, and the attached copy is provided by Elsevier for the author's benefit and for the benefit of the author's institution, for noncommercial research and educational use including without limitation use in instruction at your institution, sending it to specific colleagues who you know, and providing a copy to your institution's administrator.

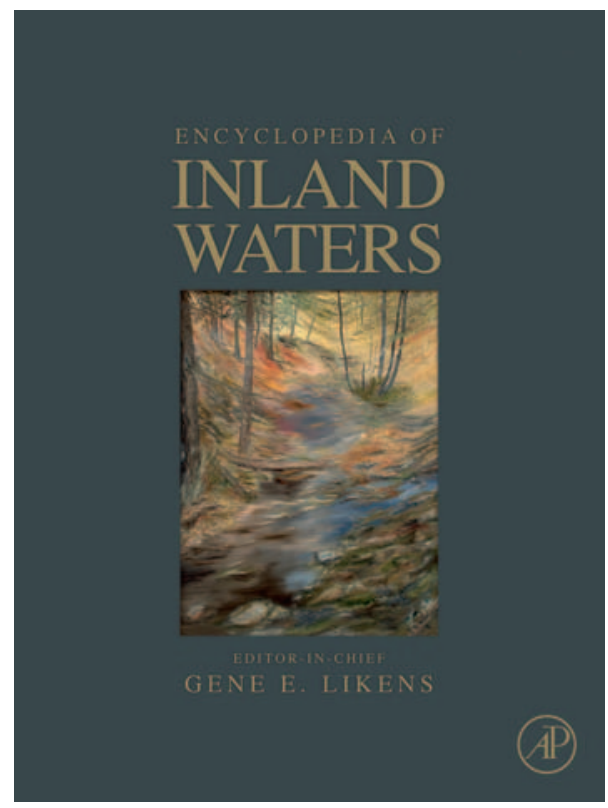

All other uses, reproduction and distribution, including without limitation commercial reprints, selling or licensing copies or access, or posting on open

internet sites, your personal or institution's website or repository, are prohibited. For exceptions, permission may be sought for such use through Elsevier's permissions site at:

http://www.elsevier.com/locate/permissionusematerial

Peeters F and Kipfer R. (2009) Currents in Stratified Water Bodies 1: DensityDriven Flows. In: Gene E. Likens, (Editor) Encyclopedia of Inland Waters. volume 1, pp. 530-538 Oxford: Elsevier. 


\title{
Currents in Stratified Water Bodies 1: Density-Driven Flows
}

\author{
F Peeters, Universität Konstanz, Mainaustrasse, Konstanz, Germany \\ R Kipfer, Swiss Federal Institute of Environmental Science and Technology (Eawag), Swiss Federal Institute of \\ Technology (ETH), Ueberlandstr, Duebendorf, Switzerland \\ (c) 2009 Elsevier Inc. All rights reserved.
}

\section{Introduction}

Vertical transport of dissolved substances and heat in lakes mainly results from two different mechanisms: (a) mixing by turbulence that is usually described as a diffusive transport and (b) density-driven exchange that can be considered as an advective transport. A typical example of the latter is convection owing to surface cooling in fall, which often leads to isothermal conditions in shallow lakes of the temperate zone. Because entrainment of ambient water limits the depth of convective plumes, density-driven transport to large depth in deep lakes usually occurs along the lake boundaries and is often the result of specific and localized processes, which are discussed later.

The important role of density-driven transport for vertical exchange in lakes becomes evident if one considers that temperature stratification typical for most lakes is characterized by a decrease in water temperature with increasing water depth. Turbulent diffusion causes heat to flow from high to low temperatures and hence typically leads to a gradual continuous warming of cold deep-water regions. Thus, on a long-term average, advective processes transporting cold surface water downwards must be sufficient to compensate for the heat flux due to turbulent diffusion. The low temperatures in the deep water are usually either the remnant of isothermal conditions generated by buoyancy-driven overturn during the cold season or originate from cold density currents propagating to largest depth. Because vertical transport due to density currents plays an important role in overall deep-water renewal and heat exchange, density driven exchange processes are central to the understanding of oxygenation and nutrient transport especially in deep lakes.

In the world's largest and deepest water bodies several processes have been identified that lead to advective deep-water renewal by density currents: river inflow, e.g., in Lake Constance, Lake Geneva, and Lake Baikal; inter-basin exchange, e.g., in Lake Lucerne, Lake Baikal, or even in the Caspian Sea; differential cooling, e.g., in Lake Geneva, Lake Constance, Lake Issyk-Kul, and Lake Malawi; thermal-bar mixing, e.g., in the Lake Ontario, Lake Ladoga, Lake Michigan, and Lake Baikal; and transport due to thermobaric instabilities, e.g., in Lake Baikal and possibly in Crater Lake. All these processes have been shown to significantly contribute to deep-water renewal in lakes, although advective transport to the lake bottom was not conclusively demonstrated in all cases. More details on the different processes are given below.

In the following, we first describe the principal characteristics of density currents and the associated signals of intrusions in vertical profiles of water constituents and temperature. Then, we present several mechanisms that lead to the generation of density plumes in deep freshwater lakes and discuss which of these processes can also be responsible for deep-water renewal in tropical and saline lakes. Finally, we discuss the potential impact of changes in the catchments of lakes and in the meteorological conditions on deep-water renewal by density currents.

\section{Characteristics of Density Currents}

Density currents are driven by differences in water density, which can result from gradients in water temperature, salinity, dissolved uncharged substances, or suspended particles and are also affected by pressure. If a water mass with higher density is situated above a water mass with lower density, the stratification is unstable and buoyancy causes the upper water mass to sink. In the sinking process ambient water is mixed into the sinking water mass and thus alters its density (Figure 1), thereby reducing the density difference between the density plume and the ambient water.

Furthermore, the properties of the ambient water change along the path of the sinking water mass. Hence the buoyancy of the sinking plume changes continuously as it sinks into deeper depth. Eventually, a depth is reached where the density of the density plume and the density of the surrounding water become equal. At this depth the sinking process ceases and the plume water spreads out laterally into the ambient water forming an intrusion (Figure 1). In many cases the sinking plume meets the lake boundary and then continues to sink along the lake boundary (Figure 1). In this case, entrainment of ambient water is limited to the upper side of the density plume and less ambient water is entrained per unit sinking depth. Hence the characteristic properties of the water within the density plume (e.g., temperature, salinity, suspended particles, dissolved oxygen) change more 


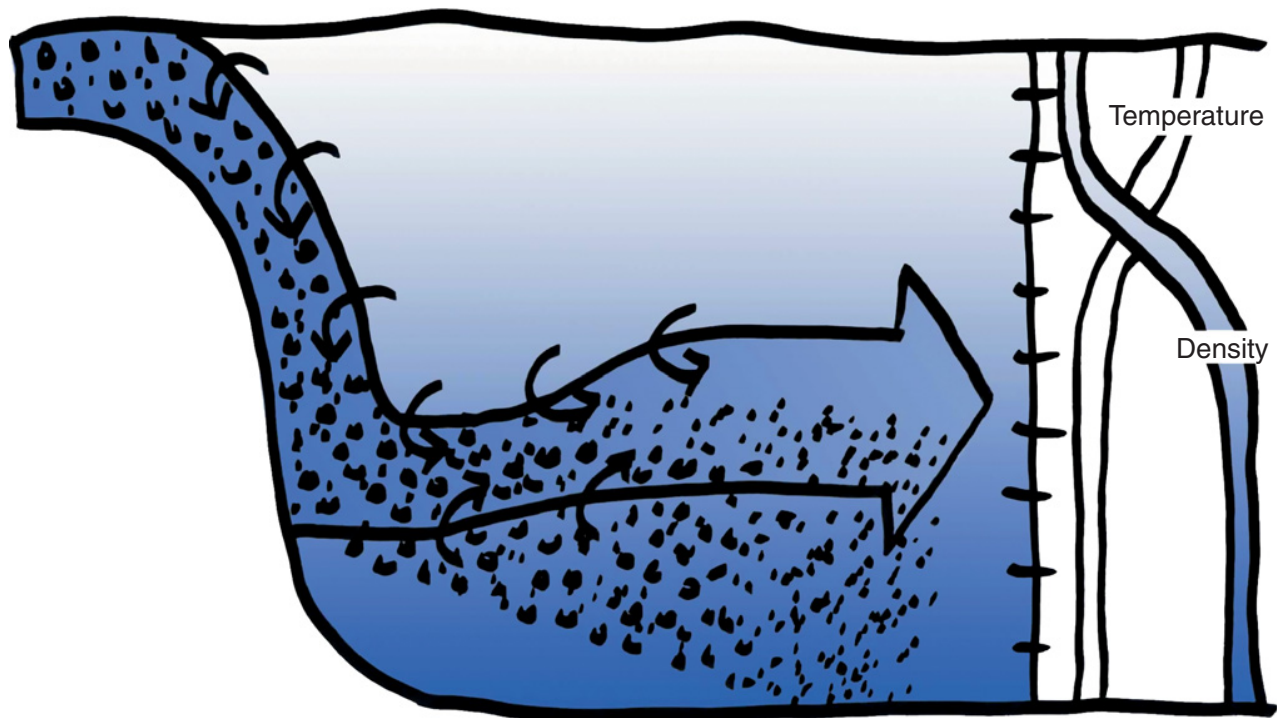

Figure 1 Schematic illustration of density currents. The shading on the left-hand side of the figure indicates an increase in density with increasing depth.

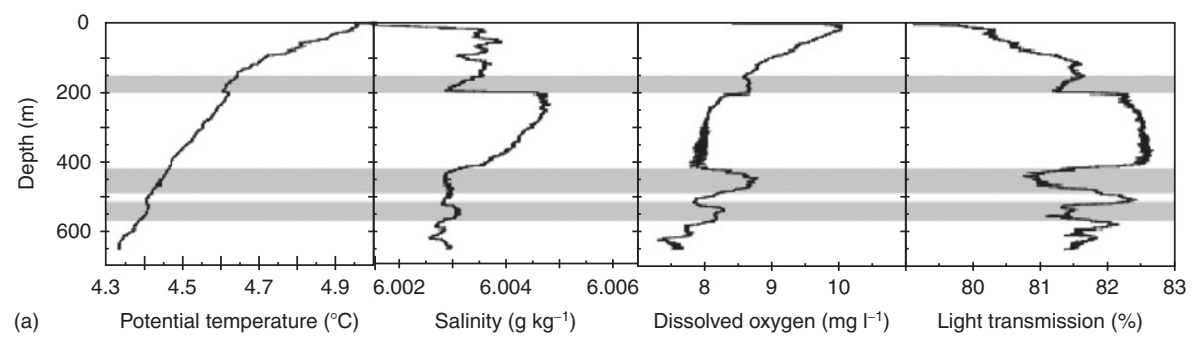

Figure 2 Intrusions as indicators of density currents. Vertical profiles of temperature, salinity, dissolved oxygen, and light transmission measured in Lake Issyk-Kul. The distinct features in these profiles suggest intrusions from density currents. Grey bars mark depth regions with high concentrations of dissolved oxygen and low light transmission, suggesting water originating from shallower depth regions. Redrawn from Figure 2 in Peeters FD, Finger M, Hofer M, Brennwald DM, and Livingstone R Kipfer (2003). Deep-water renewal in Lake Issyk-Kul driven by differential cooling. Limnology \& Oceanography 48(4): 1419-1431.

slowly and the density plumes typically can propagate to larger depths than would be possible in the open water.

The occurrence of density plumes propagating from shallow to deep water are indicated by intrusions that can be identified in CTD-profiles (conductivity as measure of salinity, temperature, and depth) and in profiles of dissolved substances and suspended particles. Figure 2 presents an example from Lake Issyk-Kul (Kyrghystan), where intrusions are characterized by a higher dissolved oxygen concentration and a lower light transmission than is observed in the ambient water.

High oxygen levels in the intrusions indicate oxygen-rich surface water that must have been transported recently because oxygen levels have not yet been significantly reduced by degradation processes.
The low light transmission in the intrusions indicates water with a high load of suspended particles suggesting either, that the water that generated the density current was enriched in suspended particles and thus may have originated from river inflow, or, that the density plume responsible for the intrusions has propagated along the lake boundary and caused resuspension of sediments during the sinking process. Temperature is usually not a good indicator of intrusions because it is a key parameter determining plume density. Thus, at the depth of the intrusion, plume water and surrounding water often have about the same temperature. However, in cases where the density plume propagates down to the largest depths, as it is sometimes the case e.g., in Lake Baikal, temperature anomalies at the lake bottom can be used to identify density plumes. 


\section{Density Plumes Generated by External Inputs}

\section{River Inflows}

The density differences required to drive density plumes originate from processes that generate horizontal or vertical gradients in water properties. An obvious example is river inflow (Figure 3).

River water usually contains an increased load of suspended particles and has a different temperature and salinity than the lake water. Hence, river inflow is commonly associated with density plumes propagating from the river mouth to larger depths. The kinetic energy associated with the inflow of the river water is usually rapidly dissipated and the horizontal density gradients resulting from the different densities of river water and lake water are the main cause of river induced transport of water masses in lakes. During summer, the density plumes induced by river inflow typically intrude at some depth within the thermocline of freshwater lakes. Because of the large temperature gradients in the thermocline, water densities change significantly within a rather narrow depth range in the lake. Hence, the probability that the density of the plume water agrees with the density in the water column of the lake is especially large within the thermocline. This fact explains that river water typically intrudes in this depth range. The depth reached by the density plumes varies during the course of the year since water properties and hence the density of lake and river water changes seasonally (Figure 3). Density currents containing a high load of
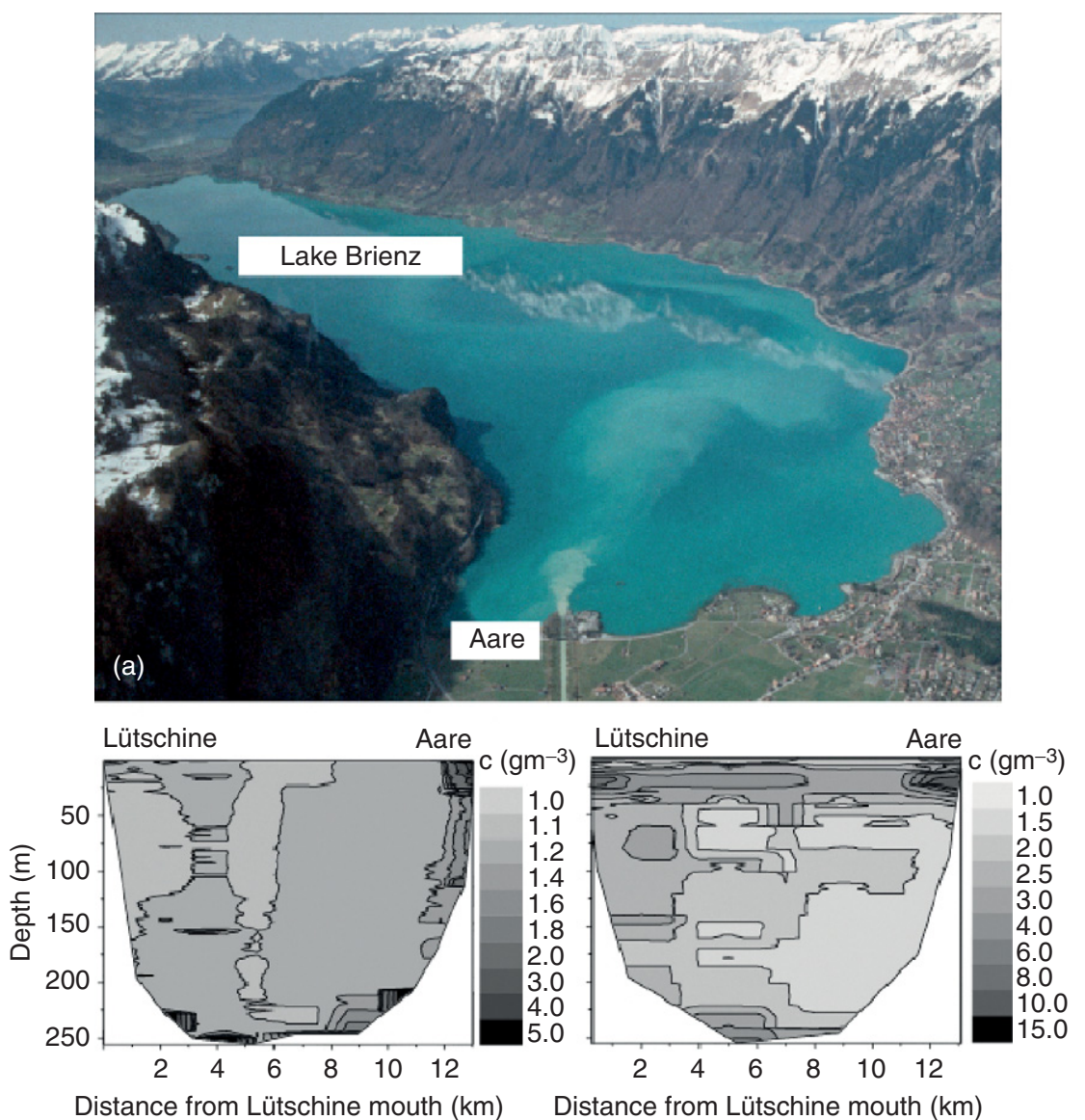

(b)

(c)

Figure 3 Density currents generated by river inflow. (a) Water of river Aare indicated by high turbidity intruding near the surface of Lake Brienz. The sharp boundaries of this surface plume indicate plunging of river water to larger depth. (b, c) Suspended particle distribution inferred from light transmission measurements in a longitudinal cross-section of Lake Brienz measured in February (b) and October (c). The particle distributions suggest that, in February water introduced by the river Aare (inflow on the right-hand side) sinks as density plume along the lake bottom towards largest depth (b). In October river Aare and river Lütchine both intrude at intermediate depth (c). (Figure 3(a) was provided by Ueli Ochsenbein; Figure 3(b) and (c) are redrawn from Figure 7(a) and 7(d) in Finger D, Schmid M, and Wüest A (2006). Effects of upstream hydropower operation on riverine particle transport and turbidity in downstream lakes. Water Resources Research 42, W08429, doi:10.1029/2005WR004751. Reproduced/modified by permission of American Geophysical Union. 
suspended particles are often called turbidity currents. Sedimentation of particles out of intrusions resulting from turbidity currents can reduce the density of the intruding water sufficiently that the depth of the intrusions becomes shallower over time. Density currents induced by river inflows usually propagate along the sloping bottom boundary before the water intrudes laterally. If the concentrations of solutes and particles are very different between the river and the lake water, the plumes can propagate down to the deepest parts of the lake. In cases where the sinking water is confined to underwater channels, e.g., density plumes propagating down the Kukui Canyon of the Selenga delta in Lake Baikal, entrainment of ambient water is reduced, and the density plume can propagate over a depth range of more than $1000 \mathrm{~m}$ down to $1640 \mathrm{~m}$ (see also Figure 4(a)).

\section{Interbasin Exchange}

River inflows not only result in localized density plumes propagating from the river mouth to larger depths but also can generate subtle large scale gradients in water properties that affect the horizontal density distribution on a basin scale. These small density gradients on a large spatial scale may contribute to the generation of density currents far from the river inflow that occur especially in the vicinity of sills separating sub-basins of the lake. This mechanism is exemplified in Figure 4 for two lakes of different size, Lake Baikal and Lake Lucerne, that both are structured into several sub-basins separated by sills.

In both lakes large scale horizontal salinity gradients are generated by river inflows introducing water with different ion concentrations into the different sub-basins. In the case of Lake Baikal, the River Selenga introduces more saline water into the Central Basin than the Upper Angara River introduces into the Northern Basin. In case of Lake Lucerne, the River Sarner Aa introduces more saline water into the sub-basin Lake Alpnach than the River Reuss introduces into the sub-basin Lake Uri. Because of the salinity gradients, the density of the water in the different sub-basins differs if temperature is the same. In Lake Lucerne the densest water can be found in sub-basin Lake Alpnach when winter cooling reduces surface water temperature to $\sim 4{ }^{\circ} \mathrm{C}$. Horizontal transport of the dense water from Lake Alpnach to the subbasin Lake Vitznau across the sill separating the two sub-basins induces a density current renewing the deep-water of sub-basin Lake Vitznau (Figure 4(b)). The density plume causes upwelling of cold dense water within Lake Vitznau. Horizontal transport of water across the sills between sub-basin results into a cascading of density driven transport within all
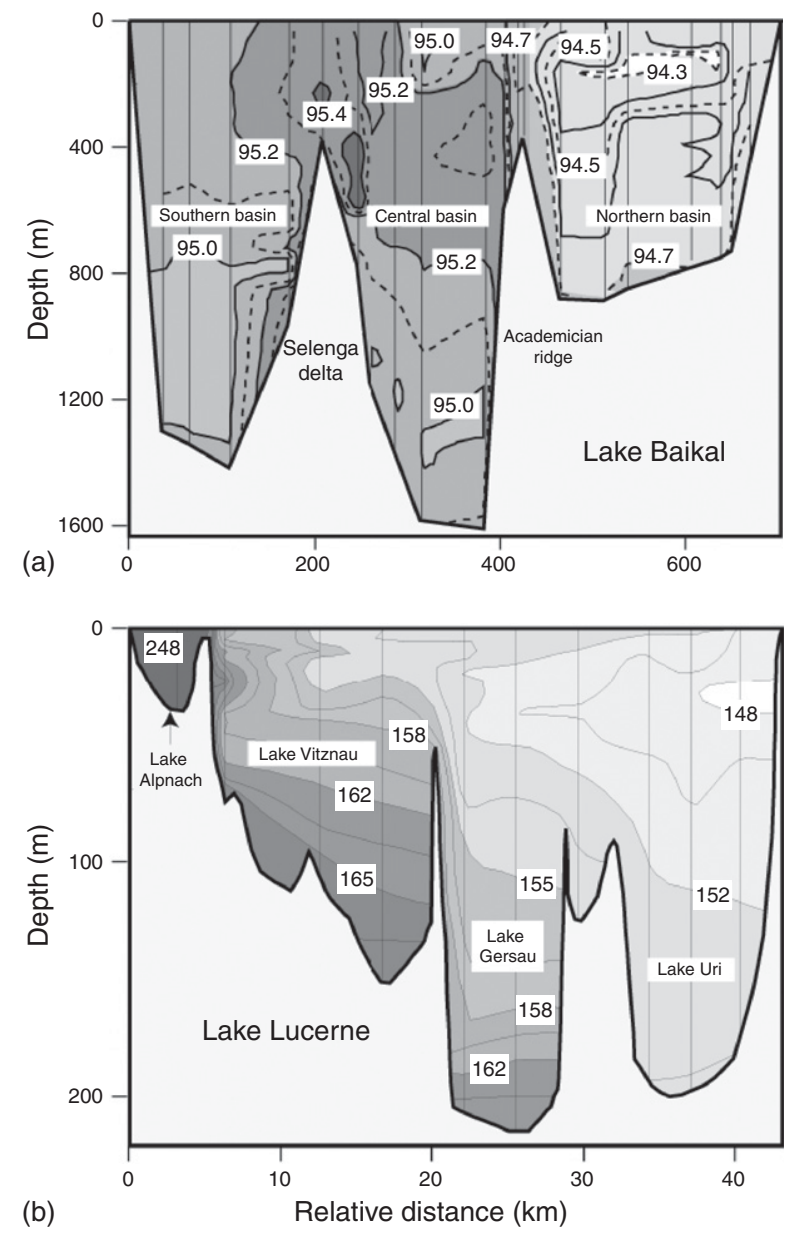

Figure 4 Density currents generated at sills between sub-basins. Vertical transects of salinity in Lake Baikal (a) and in Lake Lucerne (b). In both lakes the horizontal gradients in salinity are generated by river inflows introducing water with different ion concentration. The salinity distributions suggest that density currents are not only generated directly by river inflow as is the case in Lake Baikal at the Selenga delta (see panel a) but that density currents also occur in both lakes at the sills between sub-basins most likely driven by horizontal transport across the sill. Contours depict salinity in $\mathrm{mg} \mathrm{kg}^{-1}$. Figure 4(a): redrawn from Kipfer R and Peeters F (2000). Speculation on consequences of changes in the deep water renewal in Lake Baikal, in K Minoura (ed.) Lake Baikal a mirror in time and space for understanding global change processes, pp. 273-280. Amsterdam, Netherlands: Elsevier. Figure 4(b): drawn using data from Aeschbach-Hertig W, Kipfer R, Hofer M, Imboden DM, and Baur H (1996) Density-driven exchange between the basins of Lake Lucerne (Switzerland) traced with the ${ }^{3} \mathrm{H}-{ }^{3} \mathrm{He}$ method. Limnology and Oceanography 41: 707-721.

sub-basins (Figure 4(b)). A similar process is operating in the different basins of Lake Baikal (Figure 4(a)). Prerequisite of these density currents generated at sills between sub-basins is (1) the structuring of the lake basin into sub-basin that prevents homogenization of water properties by horizontal mixing and (2) a heterogeneous input of water properties, as e.g., the salinity by the river inflows in Figure 4. 


\section{Subsurface Inflows}

Besides the input from rivers, external water sources derived from groundwater inflows and from hydrothermal vents can generate density currents depending on the depths at which the inflows are located. Groundwater and hydrothermal water is usually highly enriched in ions and thus can cause salinity driven density plumes. Groundwater inflows into lakes are common in artificial lakes such as mining lakes or gravel-pit lakes or occur in karstic environments. Density currents due to hydrothermal vents have been reported for instance in Lake Baikal, where hydrothermal water is introduced in Frohliha Bay at a depth of $200-400 \mathrm{~m}$ and propagates as a bottom following density current down to $1400 \mathrm{~m}$ depth. In this specific case the salinity of the hydrothermal water is sufficiently large to compensate the decrease in density due to the increased water temperatures in the hydrothermal water.

\section{Density Plumes Generated by Internal Processes}

\section{Differential Cooling}

A key parameter affecting water density is temperature. However, for density currents to be induced on the basis of the temperature of water, horizontal gradients in temperature are required. Horizontal temperature gradients are generated by external surface and subsurface inflows (see earlier text) but also by internal processes. In most lakes the heat flux at the lake surface (expressed per unit area) can be considered as horizontally homogeneous because meteorological parameters and radiation do not vary significantly at the length scale of the lake basin. Nevertheless, differential cooling can generate significant temperature differences within lakes and thus generate density currents (e.g., Wellington Reservoir, Lake Geneva, Lake Constance, Lake Banyoles). Heat loss at the lake surface causes vertical convection and thus mixing of surface water with water from layers below. This process continuously mixes the cooled surface water with water from deeper layers containing heat stored during the warm season. In shallowwater regions, the reservoir of warmer deep water is exhausted earlier than in regions with large water depth. Hence, in shallow-water regions heat loss at the lake surface leads to a faster cooling of the water column than in deep-water regions. Because the cold water in the shallow-water regions has a larger density than the warmer water in the pelagic, deep-water regions, the cold water propagates downwards as a density current. Such density plumes often occur only sporadically. They are typically generated during

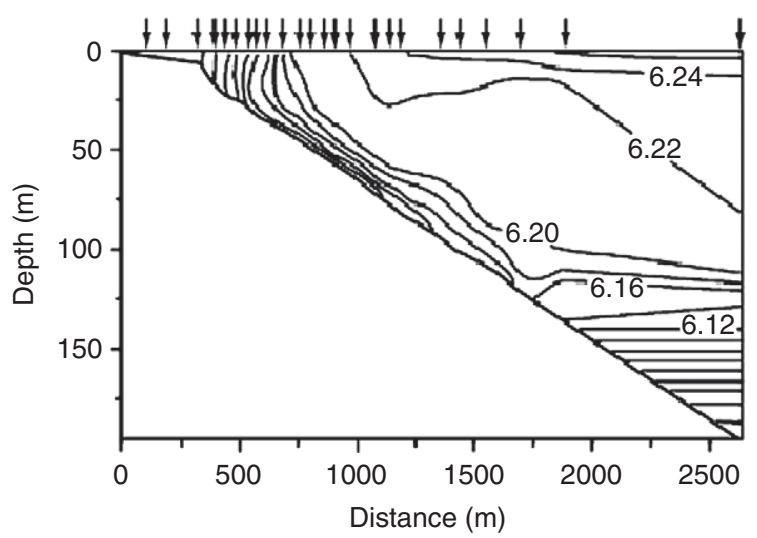

Figure 5 Density current generated by differential cooling. Contour lines represent isotherms in ${ }^{\circ} \mathrm{C}$ indicating a density plume generated by differential cooling in Lake Geneva. Note that the temperatures are well above $4^{\circ} \mathrm{C}$. The isotherms are constructed from CTD-data collected at the locations indicated by the arrows. Redrawn from Figure 2(b) in Fer I and Lemmin U. Winter cascading of cold water in Lake Geneva. Journal of Geophysical Research 107, NO. C6, 10.1029/2001JC000828, 2002. Reproduced/modified by permission of American Geophysical Union.

night-time cooling in fall as has been demonstrated in e.g., Lake Constance and Lake Geneva (Figure 5) or during events that also induce cooling such as cold fronts or monsoons.

Differential cooling can result in density driven currents from any shallow region in a lake basin. Therefore it may affect a large volume of water and thus may significantly contribute to overall vertical transport. The process is particularly effective if large shelf regions are located around a deep basin. The density currents induced by differential cooling propagate along the lake bottom and can reach large depths especially if channels exist along which the density current can propagate without significant entrainment of ambient water, as is the case e.g., in Lake Issyk-Kul. Note, that in freshwater lakes differential cooling can only generate density plumes if water temperatures are above the temperature of maximum density $\left(T_{\mathrm{md}}\right)$ which is about $4{ }^{\circ} \mathrm{C}$ at the lake surface. Cooling below $T_{\mathrm{md}}$ implies a decrease in water density and thus prohibits density plume development by differential cooling. Hence, in freshwater lakes the temperature of density plumes associated with differential cooling is at least $4{ }^{\circ} \mathrm{C}$ or higher.

\section{Thermal Bar}

Temperature-driven density currents can also result from horizontal mixing of two adjacent surface water masses, one having a temperatures above and the other below $T_{\mathrm{md}}$. Because of the non-linear temperature 
dependence of the equation of state, mixing of water masses with different temperatures always results in an increase in the mean density of the water. This process is called cabbeling. If the temperature of the mixed water is closer to the $T_{\mathrm{md}}$ than the water below, it sinks as a density plume. A so-called thermal bar develops which is characterized by a vertically isotherm water column with a temperature close to $T_{\mathrm{md}}$ separating an open water region with temperatures below $T_{\mathrm{md}}$ from a warmer shore region with temperatures above $T_{\text {md }}$ (Figure 6).

The downward flow of dense surface water at the thermal bar can cause significant renewal and oxygenation of deep water. As time progresses the thermal bar moves further away from the shore to the open water. The dynamics of this process depends on the morphometry of the lake and on the atmospheric forcing. Mixing associated with the thermal bar has been

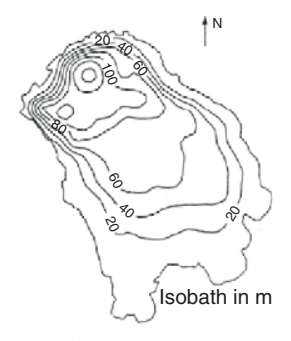

(a)
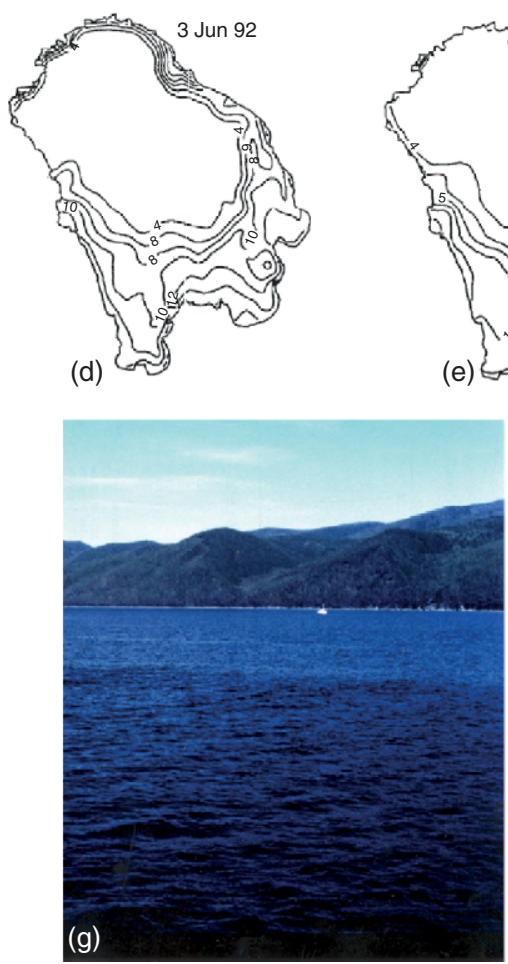

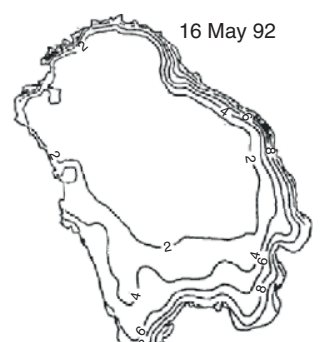

(b)

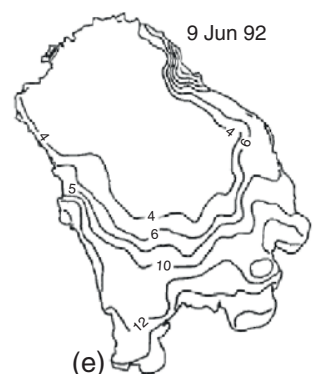

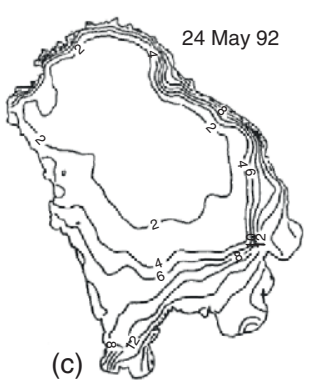

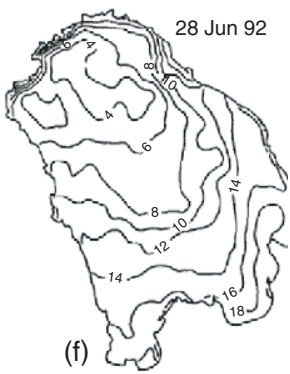

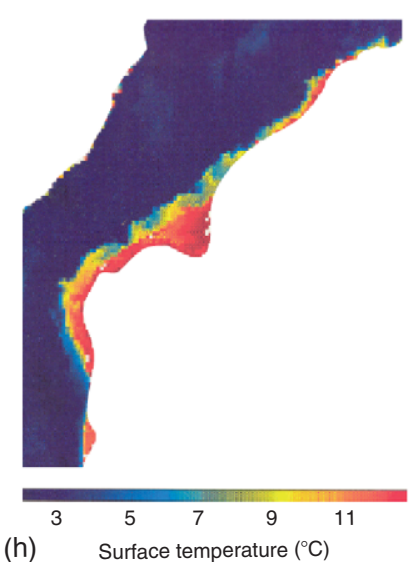

(h) Surface temperature $\left({ }^{\circ} \mathrm{C}\right)$

Figure 6 The thermal bar. The development of a thermal-bar in Lake Ladoga indicated by surface temperatures measured with satellites (a-f) and the observation of a thermal bar near Selenga delta in Lake Baikal ( $g$ and h). Panel (a) provides the morphometry of Lake Ladoga with depth contours given in $\mathrm{m}$. Panels (b-f) depict surface temperatures with isotherms in ${ }^{\circ} \mathrm{C}$. Panels (b-f) show how the thermal bar, which is located at the $4^{\circ} \mathrm{C}$ isotherm, moves towards deeper water as the season progresses. The position of the thermal bar changes more rapidly in the gently sloping shallower south-eastern part of the lake than in the steep and deep northern part. In ( $\mathrm{g}$ ), the sharp boundary between near shore water and open water indicates the position of the themal bar located near the Selenga delta in Lake Baikal. The color differences result from differences in the load of suspended particles. The water trapped near shore by the thermal bar has an increased load of suspended particles owing to the nearby inflow of the Selenga River. Panel (h) shows an image of the surface temperatures near Selenga delta derived from satellite data. Density currents are generated at the sharp transition between warm shore water and cold open water characterized by a temperature close to $4^{\circ} \mathrm{C}$. White areas are land. Figure $6(\mathrm{a}-\mathrm{f})$ are redrawn from Figures 1 and 3 in Malm J, Mironov D, Terzhevikl A, and Jiinsson L (1994) Investigation of the spring thermal regime in Lake Ladoga using field and satellite data. Limnology and Oceanography 39(6): 1333-1348. Copyright 2000 by the American Society of Limnology and Oceanography, Inc. 
reported for Lake Ontario, Lake Ladoga, Lake Michigan, and Lake Baikal. Because the thermal bar requires open-water temperatures below $T_{\mathrm{md}}$, it occurrs mainly in lakes which become ice covered in winter.

The horizontal temperature gradients required for thermal bar development are generated by differential heating during spring warming, a process similar to differential cooling. Initially in spring, when surface-water temperatures are below $T_{\mathrm{md}}$, an increase of water temperature during spring warming leads to an increase in the density of the surface waters and thus to convection. Because convection mixes the warmer surface water with colder water from below and the reservoir of the cold water from below is smaller in shallow near-shore than in deeper openwater regions the temperature in the shallow-water regions increases faster than in the deep off-shore regions. When the temperature in the shallow regions exceeds $4{ }^{\circ} \mathrm{C}$ the water column is stratified and further influx of heat is not connected to convection, but leads to an even faster increase in the water temperature. Thus, a horizontal temperature gradient typical for a thermal bar situation develops with temperatures below $T_{\mathrm{md}}$ at the surface of the open-water region and temperatures above $T_{\mathrm{md}}$ at the surface in the shallow near-shore regions. A reverse thermal bar situation with temperatures below $T_{\mathrm{md}}$ in the shallow-shore region and temperatures above $T_{\mathrm{md}}$ in the open-water region could develop in fall as a consequence of differential cooling if cooling in the shore region progresses to temperatures below $T_{\mathrm{md}}$. However, in the case of the reverse thermal bar exchange processes will be dominated by horizontal density gradients below the surface (see the section on 'Differential cooling').

\section{Thermal Baricity}

Another process that can generate density plumes as a consequence of the nonlinearity of the equation of state of freshwater is the thermobaric effect. The thermobaric effect results from the fact that $T_{\mathrm{md}}$ decreases with increasing pressure. The generation of density currents by the thermobaric effect requires a very specific temperature stratification that occurs only in few stably stratified deep freshwater-lakes, e.g., Lake Baikal or Crater Lake. To generate density currents by the thermobaric effect, water temperatures must be below $4{ }^{\circ} \mathrm{C}$ throughout the water column. The temperature in the surface layer must increase with increasing depth, whereas the temperature in the deep-water must decrease with increasing depth. Then, the temperature profile has a maximum at intermediate depth, the so-called mesothermal maximum (Figure 7).

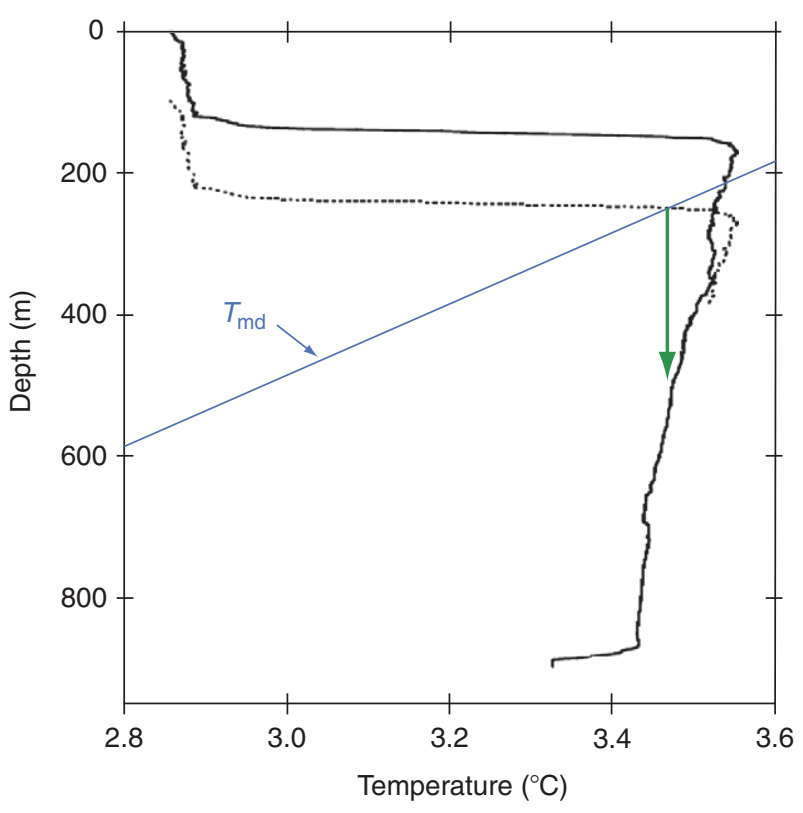

Figure 7 Schematic on the generation of density currents by the thermobaric effect. The temperature profile presented has been measured in the northern basin of Lake Baikal. The temperature of maximum density as function of depth shown for comparison is labelled with $T_{\mathrm{md}}$. Vertical displacement of the temperature profile (indicated by the dashed line) leads to a density driven vertical transport that is self supporting over the depth range indicated by the arrow.

A water column with such a temperature profile is stably stratified because of the effect of pressure on fresh water density. If the water column is displaced downwards or pressure is increased, the temperature at the mesothermal maximum is higher than the local $T_{\mathrm{md}}$ and the water column becomes unstable. Cold water from above the mesothermal maximum can sink downwards as a density plume (Figure 7). Similarly, a water mass from the cold upper layer can be pushed downwards below the mesothermal maximum to a depth where its temperature is closer to $T_{\mathrm{md}}$ than the temperature of the ambient water. Then, it will continue to sink driven by its buoyancy until the surrounding water has the same temperature as the sinking water mass. Besides the specific temperature profile in the water column the exchange due to the thermobaric effect also requires a mechanism by which the water pressure is altered substantially and/or the water is locally pushed downwards across the depth of the mesothermal maximum. Hence density plume generation by the thermobaric effect is not very common. Several investigations have claimed that the thermobaric effect may be important for deep-water oxygenation in Lake Baikal. However, the mechanism that could cause the required downward displacement in the open water column remained unclear. Recently, wind-driven Ekman transport near the coast of the 
Southern Basin of Lake Baikal has been suggested to cause thermobaric instabilities.

\section{Turbidity Currents Generated by Waves}

Internal processes not only can generate temperature gradients but also can cause gradients in suspended particles that are sufficient to drive density currents. Shear stress at the lake bottom associated with surface waves and high-frequency internal waves can induce sediment resuspension and thus increase the load of suspended particles in the water column. If the density increase induced by the change in particle load is sufficiently large to compensate vertical density stratification, turbidity currents are generated. Because the turbidity gradient is generated by the interaction of waves with the sediment, the resulting turbidity currents usually originate either near the shore at the lake surface (surface waves) or at the depth of the thermocline (high-frequency internal waves). The turbidity currents usually propagate along the lake bottom to larger depth until they intrude into the open water.

\section{Horizontal Density Currents Generated under Ice Cover}

Temperature-driven density currents can also occur under ice cover due to differential heating by solar radiation. This process is invoked if the optical properties of the ice and snow cover vary horizontally either due to a variation in the ice structure (e.g., white ice and black ice) or in the thickness of snow cover. Then, penetration of solar radiation through the ice and snow cover varies horizontally and thus induces differential heating in the surface water below the ice. This process causes convection below the ice and results in horizontal density gradients that can drive horizontal density currents. Such under-ice currents are believed to be essential for the development of algal blooms in early spring in Lake Baikal.

\section{Density Currents in Tropical and Saline Lakes}

In tropical lakes and also in saline lakes several of the processes mentioned above do not occur. Because the development of a therma bar requires a lateral transition of water temperature from above to below $T_{\mathrm{md}}$ at the lake surface, a thermal bar never occurs in tropical lakes where water temperatures are above $4^{\circ} \mathrm{C}$ all year round and thus always exceed $T_{\mathrm{md}}$. Because $T_{\mathrm{md}}$ decreases with increasing salinity reaching freezing temperature at about $25 \mathrm{~g} \mathrm{~kg}^{-1}$, thermal bar development and the associated density currents also do not play an important role for the vertical exchange in saline lakes. The same arguments exclude the thermobaric effect as a significant cause of density currents in tropical and saline lakes.

In tropical lakes temperature gradients play the dominant role in the generation of density currents because at high water temperatures, slight temperature gradients imply large differences in density. Therefore, salinity gradients play a smaller role for density plume generation in tropical lakes than for lakes of temperate regions during the cold season. Convection due to night-time cooling and density currents due to differential cooling and river inflows can be expected to be the most important processes for advective deep-water renewal in tropical lakes.

In saline lakes, however, river inflows usually cannot drive density currents because rivers typically introduce freshwater that in most cases has a much lower density than the saline lake water, even if the inflow has a low temperature. For example water with a salinity of $4 \mathrm{~g} \mathrm{~kg}^{-1}$ and a temperature of $24^{\circ} \mathrm{C}$ has a greater density than freshwater with $4{ }^{\circ} \mathrm{C}$. Hence, river inflows can only directly drive density currents in saline lakes, if the riverine water carries a substantial load of suspended particles. Nevertheless, in saline lakes river inflows can generate large scale differences in salinity and thus may indirectly lead to density currents at sills induced by inter basin exchange as is probably the case in the Caspian Sea. Another process that is likely to cause density currents in saline lakes is differential cooling. In contrast to freshwater lakes this process can trigger density currents with temperatures well below $4{ }^{\circ} \mathrm{C}$ and even down to freezing temperature, because $T_{\mathrm{md}}$ can be substantially reduced or even does not exist depending on the salinity of the water.

\section{Impact of Changes in the Environmental Conditions on Density Currents and Deep-Water Renewal}

Changes in climatic conditions and human activities in catchments may affect density currents and thus vertical mixing in lakes. An increase in precipitation and in the percentage of the land made impervious by human development typically leads to a higher discharge of rivers. Enhanced river discharge is usually associated with increased erosion and a higher load of suspended particles in the river water such that density currents will propagate to larger depth. Enhanced deep-water renewal is thus anticipated in freshwater lakes. In saline lakes, however, the increase in freshwater input associated with increased precipitation reduces the density of the surface waters 
and thus can significantly limit the generation of density currents. Consequently, deep-water renewal may be reduced or suppressed. Deep-water exchange decreased drastically as a consequence of increased riverine discharge in the Caspian Sea and in Mono Lake, CA.

Water storage dams in the catchments of lakes have the opposite effect on density currents than soil sealing. Retention by water storage dams reduces peak discharge and the load of suspended particles in downstream rivers. This results in a decrease in the intensity of density currents and in the depth of intrusions in lakes located downstream of dams.

Climate warming can lead to a reduction of deepwater renewal in lakes because additional input of heat at the lake surface may result in an increase in density stratification of the water column and in an extension of the stratified period. Persistence of the increased stratification over many years likely depends on the lake's latitude and depth and whether warming is intensified in winter or summer or, for tropical lakes, during the monsoon period or during less windy periods.

In a warmer climate, however, mixing in freshwater lakes due to density currents associated with the thermal bar and/or the thermobaric effect may cease, if climate warming leads to an increase in surface water temperature to values above $4{ }^{\circ} \mathrm{C}$ all year round, i.e., to values above $T_{\mathrm{md}}$. Because density is a nonlinear function of temperature, warming of surface water may also shift the relative importance of turbidity and salinity gradients towards temperature gradients as agent to drive density plumes.

The potential consequences of environmental change on density currents are exemplified for Lake Baikal, the deepest lake on earth. Because of the peculiar temperature profile with the mesothermal temperature maximum (see Figure 7), deep-water renewal in Lake Baikal is predominantly driven by salinity differences between river and lake water and between the basins of the lake. The salinity differences result in density plumes associated with riverine inflows and inter-basin exchange. Hence, changes in the catchments leading to an increase in the concentration of dissolved ions and suspended particles in river inflow will intensify deep-water mixing by density plumes. Climate warming on the other hand will not severely affect density plumes and thus deep-water renewal in Lake Baikal, as long as the lake has an annual ice cover. Higher air temperatures most likely result in a shift of ice break-up to earlier times in the year, but will not have an affect on the thermal conditions immediately after ice break-up. Hence, the conditions required to generate density plumes will not change, but may occur earlier in the season.

In summary, density currents significantly contribute to deep renewal, especially in deep and very deep lakes. The density currents can result from a variety of processes. Which of these processes are relevant in a specific lake depends on the temperature regime of the lake, its salinity and also its morphometry. The environmental conditions, e.g., precipitation in the catchments and heat flux at the lake surface affect the occurrence of density currents and the depth reached by the density plumes. Hence, changes in the environmental conditions will have consequences for deep-water renewal and oxygenation of deep lakes not only because of a change in turbulence levels, but also by their effect on the intensity of density currents.

See also: The Benthic Boundary Layer (in Rivers, Lakes and Reservoirs); Density Stratification and Stability.

\section{Further Reading}

Aeschbach-Hertig W, Kipfer R, Hofer M, Imboden DM, and Baur $H$ (1996) Density-driven exchange between the basins of Lake Lucerne (Switzerland) traced with the ${ }^{3} \mathrm{H}-{ }^{3} \mathrm{He}$ method. Limnology and Oceanography 41: 707-721.

Fer I and Lemmin U (2002) Winter cascading of cold water in Lake Geneva. Journal of Geophysical Research 107: NO. C6, 10.1029/2001JC000828.

Finger D, Schmid M, and Wüest A (2006) Effects of upstream hydropower operation on riverine particle transport and turbidity in downstream lakes. Water Resources Research 42: W08429, doi:10.1029/2005WR004751.

Fischer HB, List EJ, Koh RCY, Imberger J, and Brooks NH (1979) Mixing in Inland and Coastal Waters. San Diego, CA: Academic Press.

Hamblin PF and Carmack EC (1978) River induced currents in a fjord lake. Journal of Geophysical Research 83: 885-899.

Hohmann R, Kipfer R, Peeters F, Piepke G, Imboden DM, and Shimaraev MN (1997) Processes of deep water renewal in Lake Baikal. Limnology and Oceanography 42: 841-855.

Malm J, Mironov D, Terzhevikl A, and Jiinsson L (1994) Investigation of the spring thermal regime in Lake Ladoga using field and satellite data. Limnology and Oceanography 39: 1333-1348.

Monismith SG, Imberger J, and Morison ML (1990) Convective motions in the sidearm of a small reservoir. Limnology and Oceanography 35: 1676-1702.

Peeters F, Finger D, Hofer M, Brennwald M, Livingstone DM, and Kipfer R (2003) Deep-water renewal in Lake Issyk-Kul driven by differential cooling. Limnology and Oceanography 48: 1419-1431.

Weiss RF, Carmack EC, and Koropalov VM (1991) Deep-water renewal and biological production in Lake Baikal. Nature 349: 665-669.

Zilitinkevich SS, Kreiman KD, and Terzevik AY (1992) The thermal bar. Journal of Fluid Mechanics 236: 27-42. 